\title{
Canadian Contemporary Music in the Twenty-First Century: A Review of Four Recordings
}

Gravity and Grace: Music of Allan Gordon Bell. Land's End Chamber Ensemble with James Campbell, clarinet. Toronto: Centrediscs CMCCD 19013, 2013. 1 compact disc (75:40). Contents: Field Notes (16:36) - Phénomènes (12:10) - Sweetgrass (27:34) - Trails of Gravity and Grace (19:20).

I Am in Need of Music: Songs on Poems by Elizabeth Bishop. Suzie LeBlanc, soprano; with various performers and ensembles. Toronto: Centrediscs CMCCD 19413, 2013. 1 compact disc (66:14) + 1 DVD (36:00). Contents: Silken Water: The Elizabeth Bishop Suite / Alasdair MacLean (11:55) - Sunday, 4 A.M. / John Plant (15:06) - Sandpiper / John Plant (7:17) - A Short, Slow Life / Emily Doolittle (9:14) - Four Songs / Christos Hatzis (22:42).

War of Angels: The Orchestral Music of T. Patrick Carrabré. Winnipeg Symphony Orchestra; with various conductors. Toronto: Centrediscs CMCCD 18513, 2013. 1 compact disc (62:13). Contents Contents: Inuit Games (8:22) - Symphony No. 1, "The War of Angels" (26:48) Symphony No. 3 (17:07) - The Dragon's Tail (9:46).

Woman Runs With Wolves. Beverley Johnston, percussion; with various performers. Toronto: Centrediscs CMCCD 18913, 2013. 1 compact disc (63:01). Contents: Arctic Dreams / Christos Hatzis (6:41) - Rant! / Tim Brady (9:10) - Grieving the Doubts of Angels / Micheline Roi (11:57) - In the Fire of Conflict: I. Rescue Me / Christos Hatzis (6:05) - In the Fire of Conflict: Il. Call Your Name / Christos Hatzis (4:02) - Woman Runs With Wolves / Alice Ping Yee Ho (14:12) - Summit / David Occhipinti (1:55) - Up and Down Dubstep / Laura Silberberg (8:59).

Writing in 2010, Heather Mac Donald argued that we live in a golden age of classical music. "Never before," she notes, "has so much great music been available to so many people, performed at levels of artistry that would have astounded Berlioz and his peers." She adds that "more people listen to classical music today, and more money gets spent on producing and disseminating it, than ever before. ${ }^{11}$ This does not deny the daunting challenges faced by arts organizations in the second decade of the twenty-first century. The ease of repetition enabled by recorded technology puts an enormous strain on the excessively limited canon. The fight for audiences forces institutions to adopt adventurous approaches to programming that are both varied and inclusive. Finally, although we can celebrate that the wages of orchestral musicians today are much higher than they were for their nineteenth-century counterparts, it has become

1. Heather Mac Donald, “Classical Music's New Golden Age," City Journal 20 (Summer, 2010), http://www.city-journal.org/2010/20_3 urb-classical-music.html. 
prohibitive to use the orchestral forces that were summoned by Mahler and Bruckner as a matter of course.

If the situation is difficult for performances and recordings of a standard repertoire established and celebrated by the canon-revering twentieth century, it is even more so for contemporary classical music. In this case, there is the added weight of being forced to compete with the music of the past to an extent that is unimaginable at any other time in history. There is also the challenge of overcoming perceptions that have stigmatized modern music as unlistenable, inaccessible, and incomprehensible. In order to succeed, contemporary classical music must regain a sense of purpose, relevance, and legitimacy. As Colin Eatock has suggested, "the goal should be to bring classical music back into the everyday lives of everyday people."2

Despite the challenges facing the classical music industry today there is promising potential in contemporary music. Clearly the greatest opportunity arises from adding fresh alternatives to the limited canon of done-to-death masterpieces. Of course for this to happen, the music must embody the values of the contemporary world to address social and cultural concerns that are relevant and meaningful to twenty-first-century listeners. This could include music of both local and global significance and acknowledge the vast number of styles familiar to today's listeners, ranging from popular music to contemporary techniques to elements from the music of various cultures around the world. In contrast to the music of the past, which is often criticized as remote and inaccessible, contemporary music can emphasize a direct and vibrant connection among composer, performer, and audience. In many cases, the composer is aware of, and writes to, the strengths of the musicians and the situations in which the music will be heard. The performers, in return, often have a personal connection to the composer that allows them to interpret or present the music in a way that animates it for the audience. Finally, current technology and media offer new ways to present and market this music so that it can have a stronger impact on its audience.

By reviewing as a group this collection of four different and unrelated compact disc recordings of contemporary Canadian music, I am seizing an opportunity to assess the ways these specific ensembles, individual performers, and composers navigate the challenges of presenting contemporary classical music in the twenty-first century. Together these four discs present twenty compositions written between 1996 and 2012 by twelve different composers. Although the repertoire encompasses an assortment of styles presented in music ranging from solo performer to chamber ensembles to large orchestra, there is a remarkable consistency in the ways all four recordings reach out to audiences through innovative programing; by establishing connections among the composers, performers, and listeners; in the high level of the

2. Colin Eatock, "What's Wrong with Classical Music?" 3 Quarks Daily (Monday, October 4, 2010), http://www.3quarksdaily.com/3quarksdaily/2010/10/whats-wrong-with-classical-music.html. 
performances; and through strategies of advocacy and promotion. The four discs also reveal two basic approaches common in contemporary music. The first, as demonstrated in War of Angels and Gravity and Grace, is a composer-centred approach in which all the pieces on the disc are by a single composer. The second, as demonstrated in I Am in Need of Music and Woman Runs with Wolves, is a performer-centred approach in which a single performer or ensemble assembles or, in many cases, commissions or inspires, a group of works by different composers.

Of the two composer-centred recordings under consideration here, War of Angels, in its presentation of symphonic works by a single composer, T. Patrick Carrabré, would seem to align closest to conventional approaches. Yet even in this familiar format there are differences. The four works were recorded by the Winnipeg Symphony Orchestra, an ensemble that has embraced the concept of playing the music of living composers through the internationally recognized New Music Festival. The orchestra is familiar with Carrabré who was for six years composer-in-residence and co-curator of the festival, and this relationship is apparent in the music. Carrabré writes to the strengths of the orchestra, which performs his music with vigour and sensitivity. The issue of the higher costs associated with recording four different pieces for large orchestra seem to have been minimized by using $C B C$ recordings made between 1997 and 2004: one suspects that the recordings were made at the time of the initial public performances so that a single preparation served for the concert performance, the commercial recording, and possibly also radio broadcasts. Carrabré writes mainly for conventional forces in a way that is novel yet accessible. Regardless of whether Carrabré is attaching an extra-musical concept to his music, the pieces appear to follow a dramatic narrative. The vivid, dark harmonies, repressed intensity, driving rhythms, and an emphasis on percussion that can be found throughout these pieces makes the music strongly compelling. Although the symphonic works conform closely to traditional models of the programmatic symphony and tone poem, Inuit Games is a wonderful cross-cultural project for Inuit throat singers and orchestra that was commissioned for a concert featuring the Inuit singer-songwriter, Susan Aglukark. Carrabré's understanding of his audience is apparent in the CD liner notes. He is able to relate his ideas behind the compositions in a way that is personable and engaging.

The potential to achieve a close relationship between composer and performer is even stronger in chamber music, and this potential is realized beautifully in Gravity and Grace. The musicians of Land's End Chamber Ensemble have been friends and collaborators with composer Allan Gordon Bell since the 1980s, and they clearly admire his work and share in his vision. The CD project was initiated by the ensemble to celebrate Bell's sixtieth birthday in the hope that it would generate a wider audience for his work. Bell, for his part, contributed Field Notes, a new work for clarinetist James Campbell and Land's End that was commissioned specially for the recording. Field Notes ultimately was awarded a Juno Award for Best Classical Composition in 
2014. The attachment the Land's End musicians feel for Bell's music is immediately apparent. Bell writes with a profound spiritual quality that is deeply grounded in the landscapes and geological features of western Canada and extends to the elements and inhabitants of this region as well. The compositions on this recording express Bell's ideals in a variety of ways. He references specific locations of the prairie landscape, evokes the songs of prairie denizens such as coyotes and birds, traces the graceful flight of prairie falcons, and touches on the Indigenous rituals surrounding the sweetgrass that grows wild in the region. The one slight departure occurs in Phénomènes in which Bell responds to the elemental imagery and raw energy of the paintings of Canadian artist Paterson Ewen rather than to nature and landscape directly.

Whereas composer-centred recordings achieve a natural coherence by presenting the music of a single composer, many performer-centred recordings accomplish this by finding a common theme to unify the compositions. This is apparent even in a recording as strikingly diverse as Woman Runs with Wolves. In this case, all of the compositions were either written for percussionist Beverley Johnston or reworked for her from pre-existing pieces, and they are all meaningful to her in some way. As she points out in the liner notes, "all [of] the works represent, in some form, the dichotomy in life between chaos and order, destruction and creation, nature and civilization." The pieces on Woman Runs with Wolves embrace popular music and popular culture by presenting a kaleidoscope of eclectic styles ranging from edgy dubstep, rap, and sampled material to Inuit throat singing and one of Rick Mercer's legendary rants. There is also an acknowledgment of a paradox that exists in classical music today: although classical music is mostly written for concert performance, it is very often heard and disseminated in a recorded format. Johnston exploits this feature by using the recording process to add overdubs, incorporate a large array of percussion instruments, make use of her singing and speaking voice, and feature several pieces that incorporate audio playback.

The final disc under consideration, I Am in Need of Music, is part of a project that drew together performers, composers, and audiences around the central figure of the Pulitzer-prize winning poet, Elizabeth Bishop. The project began with soprano Suzie LeBlanc's discovery of a leaflet about Bishop at the church in Great Village, Nova Scotia, that was located across the street from the house in which Bishop grew up. This led to the idea of celebrating Bishop's centenary in 2011 with new settings of her poetry by Canadian composers. The idea was imbued with a strong sense of local and historical significance and it clearly spoke strongly to the four composers who contributed moving and sensitive settings of Bishop's poetry. All of the compositions are written in modern yet accessible styles, but this is especially apparent in the songs by Christos Hatzis which draw their inspiration from big-band era pop songs, folk and pop idioms of the sixties, the waltzes of Richard and Johann Strauss, and Broadway musicals. What is most impressive is the extent to which the organizers were able to foster an interest in new music and bring it to a wider audience. Bishop's centenary became a cultural event with the 
creation of new works, a concert with Symphony Nova Scotia entitled Elizabeth Bishop in Words \& Music that featured the new compositions along with video projections, and the CD recording of the music. The CD package also includes a bonus DVD, Walking with EB. On it, LeBlanc and filmmaker Linda Rae Dornan retrace Bishop's 1932 walk across the Avalon Peninsula in Newfoundland and document their own experiences of the landscape and their connections to Bishop and her poetry. Although only thirty-six minutes in length, the film brings Bishop and her world vividly to life and provides valuable insights into, and perspectives on, the music contained on the CD.

Overall these four recordings demonstrate a strong passion for new music among composers and performers. The performers advocate new music through commissions or events such as the Elizabeth Bishop project and bring it to listeners in engaging formats such as Winnipeg's New Music Festival. Beverley Johnston has an impressive history of commissioning and performing new music and Land's End was created to explore the boundaries of contemporary music which they foster not only in their concert series but also in an annual competition for emerging composers in western Canada. The dedication to the music is also apparent in the performances. The performers clearly care deeply about this music and are heavily invested in bringing it alive for the audiences. This is also music that we, as listeners, should care about. This is music that addresses social issues and concerns, has local and historical significance, and is presented using musical styles and compositional approaches that are meaningful to today's listener. Based on the evidence on these recordings, Canadian contemporary music is thriving.

\section{J. Drew Stephen}

University of Texas at San Antonio 